\title{
The Green and the Blue
}

\author{
A New Political Ontology for a Mature Information Society
}

\author{
Luciano FLORIDI (Oxford)
}

\section{Introduction}

In this article, I present some ideas that I hope may help improve political thinking and practice in a mature information society. ${ }^{1}$ The ambition is quintessentially philosophical: trying to understand and improve the world, to the extent that each of us can contribute, in this case with some intellectual work. That is all. It is not a little, I realize, but it is not much either. It is the usual paradox: how important is a vote, or, in this case, a conceptual contribution? As much as a grain of sand on the beach: one counts for nothing, two are still nothing, but millions of grains can make a significant difference, if only because, without them, the beach would not exist. This is the relational value of aggregation. The ambition is therefore philosophical, but also aggregative, because I hope that the ideas expressed in this article may be useful and find some follow-up.

The ideas presented are philosophical, but they want to avoid being too abstract, so as not to be ultimately inapplicable. However, they do not want to be overly applied either, because it is up to politics to discuss and transform ideas into specific actions. The point is to find the right distance between politics as pure political science and politics as a practice of policy. For this reason, the correct term to describe the ideas in this article can be borrowed from medicine, where the most abstract theory of a Nobel laureate and the most applied practice of a family doctor are never dissociated: they are translational ideas. They have the objective of articulating a foundational reflection that can be translated into concrete strategic guidelines, for the realization of specific political, legislative, economic, organizational, and technical actions. It is not an original idea: good philosophy has tried to be translational at least since the time of Socrates. We only lacked the right word.

Offering ideas for improving politics is a political operation in itself. This is because today politics is emerging more and more as a relational activity (the central theme of this article), and it is typical of some of the relational phenomena to absorb

\footnotetext{
${ }^{1}$ It should be clear contextually, but let me clarify that in this article I only refer to good ideas that can influence politics, not to any good ideas in general, for example scientific ideas. This article summarises some of the theses developed in Floridi (2020).
} 
also their negation. For example, lack of interaction is a form of interaction, as an omission; lack of communication is a form of communication, because silence also speaks volumes about who is silent, and about what they are silent; and lack of information is a form of information, because it has a communicative value, given that a question without an answer is always informative with respect to the need to know something, and to its lack of satisfaction. Politics belongs to this kind of relational phenomena. Not doing politics-for example abstention-still remains a political behaviour, at least insofar as it delegates political decisions to others. It is therefore an illusion to think that we can live in a society and not be political. Only solitude can be genuinely apolitical (not solipsism, which is only the state of believing that one is alone). Even with only two people in a desert island, like Robinson Crusoe and Friday, politics is already inevitable. For this reason, Aristotle was partly right: we are all political animals, because even the attempt not to be political remains a political act. But he was wrong in thinking that we are voluntarily, continuously, and rightly so. None of the three conditions is ever entirely taken for granted, and today all are unfulfilled, for the following reasons.

First, because, in every democracy that exists today, we are political even involuntarily, that is, against our explicit will, not only unconsciously. And this can generate irritation and conflict since we cannot escape politics even when we want to reject it because it has disappointed us and we do not like it.

Second, because, in a mature information society, we are never "always political", but more and more often we are political intermittently, when social attention is called to express its judgment. For this reason, the communication mechanisms of politics are almost indistinguishable from the communication mechanisms of marketing, especially in countries where comparative advertising is permitted ("this product is better than that one"). The medium pursues the same goal: to attract or renew and then to keep the attention of the people (be they clients or citizens) on a particular theme, be it a new product or a new political issue. If this happens often, the result is a constant renewal of the stimulus, which requires increasingly intense doses to have some effect. Marketing has its own pace, and so does politics. If politics is the constant pursuit of populist consensus, each political actor will inevitably be tormented by his or her competition, and therefore devoid of control over their diary and agenda. Every move must be countered by another move, everyone chasing one another, no one driving. People do not become used to political solutions but only addicted to the communication that advertises them (or indeed that advertises new political problems). Not all current politics shares this asynchrony, but the fact remains that today we need the political call to take action; and yet we are also addicted to this call, requiring an ever-increasing intensity or diversification to be noticed (it doesn't matter what one communicates, it simply matters that it is "new" or else communicated in a "new" way)-and the use of emergency or alarmism as a part of normal messaging. Brexit is a very fitting example. The populist marketing of a single problem, that is, immigrants and hence the European Union, and therefore of the exit from the Union as the only (and stridently) stated solution, has been successful for a thousand reasons, including because of the constant renewal of the advertising message, unrelated to the real needs of the custo- 
mers-citizens. In order to distance ourselves from all this, the following pages should be imagined as read out in a low and quiet voice-without alarmism, reevaluating a rhetoric of content (semantics) over that of mere form (syntax), and favouring a strategic not a tactical timing, that is, an approach that does not simply react to the news of the political market.

And finally, the third reason is that Aristotle was only partly right about us. He was justified in calling us political animals, but the problem is that, when we are asked to be political, we can easily be so in the wrong way (rather than "rightly so")when politics becomes a matter of power serving itself, of promoting private interests, or of a majority abusing a minority.

From these reasons it follows that, in any society, politics can never be denied, but can easily be degraded. The politics of populism, of nationalism, of intolerance, of violence, of extremism, of selfish interests, of passive and indifferent abstention, and at times of sterile protest ... all these many kinds of self-centred politics also manifest an understandable dissent against the impossibility of non-politics. But the more such negative politics is expressed, the more it remains a political contribution, generating further and even more negative political reactions, until it ends up occupying all the space of political dialogue, in a downward spiral of negativity that eventually leads to useless polarization and a corruption of society's confidence in its political abilities. Today, there is no lack of good policies to be realized, because there is a lot of intelligence around. What is missing is the right approach to remove the obstacles to implementation, because goodwill, while as abundant as intelligence, has become estranged from politics. By not doing politics, goodwill turns to self-destruction, because it leaves room for bad politics, which in turn negatively influences the exercise of goodwill. The frustration of reason joins the optimism of the heart (to paraphrase Gramsci) in regretting so many opportunities wasted, while the world is in such great need of them.

In the light of these problems, the political ideas expressed in this article are intended to be constructive, non-destructive, and super partes, not party-oriented or ideological. Not for anti-party reasons. As I argued above, anti-partitism and anti-politics now belong to the most widespread and sometimes "smart" partisan and political rhetoric. But because these ideas, to the extent that they can be useful, are offered to any political force that is interested in using them to govern better. In other words, the ideas presented here are open source and without constraints: adoptable and adaptable by anyone who thinks that they may have some value.

The title of this article takes up an idea, expressed in an article I wrote some time ago, on the need to unite green environmental policies (green economy and sharing economy) with blue digital policies (service economy), in favour of an economy of experience, that is, centred on the quality of relationships and processes, and not so much of consumption, that is, not so much centred on things and their properties. ${ }^{2}$ These are topics to which I shall return in the following pages. Here, I would like to explain in what sense the ideas offered would like to be naïve.

\footnotetext{
2 "The Green and the Blue: Naïve Ideas to Improve Politics in a Mature Information Society", in: The 2018 Yearbook of the Digital Ethics Lab, 183-221.
} 
The ideas presented are naïve not in the sense that they are void of any "cunning of reason" (to use a Hegelian phrase) in the clever calculation of conveniences, or of opportunistic cynicism in the evaluation of power. But that they were intentionally emptied of it, in retrospect, and with disenchantment, but without disappointment. Think of the difference between a new coffee machine, which is void because it has never made any coffee, and a used and empty one, which contains no coffee because it has been emptied. Coffee tastes better when made in the second one, the one that has been emptied, not in the first, which is still void. In other words, the patina of reflection improves itself. This is why historical memory has enormous value, as a reminder of a presence of meaning, which requires a mental life to be appreciated, and not as a mere recording of facts, for which a digital system is sufficient.

This emptying-or "naïve-fication" to use a neologism-has been pursued in this article to give space to social altruism; to the intergenerational pact; to care for the world; to the sense of common homeland; to civil and ecological liability; to the political vocation as a service towards institutions, the State, and the res publica; to a cosmopolitan and environmentalist vision of the human project, understood as a society and life that we would like to see realized in the world; and finally the possibility of talking about good and bad politics. These relations are all qualified by many values, as we shall see later. Today it takes courage to use these expressions, because political ingenuity is seen as nonsense, for incompetent beginners, or as crafty cunning, for cynical politicians. Many deride it, or suspect it to be mere rhetoric, behind which other meanings, ambitions, messages, or manoeuvres can be hidden, to be deciphered according to the refined art of the most advanced political gaming. These many can stop reading this article. It is not written for them, because it means only what it shows and does not intend to show anything but what it says (to paraphrase Wittgenstein), with the simplicity that should qualify the most serious and mature politics. Or as Paul of Tarsus says in his Letter to Titus: "Everything is pure for the pure [Omnia munda mundis]; but nothing is pure for the polluted and infidels; their mind and their conscience are contaminated (1:15)". The contaminated should take no offence, but they will not understand it.

By adopting this "naïve" approach, this article does not disregard Machiavelli or Hobbes, Locke, Rousseau, Kant, Mill, or Rawls. Yet in the end it is based, laically, on the most forward-looking strategy contained in Matthew 18:3 "if you do not become like children you will never enter". Ingenuousness (naivety) is the point from which we start and to which we must return as ingenuity after the enriching path of reflection. It is sometimes the highest degree of sophistication to which we can aspire. Ithaca is a good analogy. And if this "forward" return to naivety (not backwards regress) perhaps cannot save the soul, maybe it can save politics. For this reason, a more adequate title for this article could be, in a less arrogant and ambitious way, "ideas that would like to be naïve".

Europe needs good ideas for a political government strategy that values and promotes its potential at best, not so much as a post-industrial society, but as a mature information society. The Union is emerging from a long period of crisis, at least as regards the economy, if not also the social aspects (especially in terms of the fracture of the social pact, even intergenerational, reduction and impoverishment of 
the middle class, less social mobility, and polarisation of opportunities that are not fairly equal), political (especially in terms of crisis of trust in institutions, populism, and personalization of politics), and cultural (national identity, immigration, role of Europe in a globalised world). In this delicate phase of recovery, the point is not being original at all costs, or imitating the US or China or other political realities, but recognizing and taking full advantage of the specific strengths of the many Europes that the EU contains, while reducing their weaknesses, and above all identifying the obstacles that do not allow these two operations. In light of this strategy, the wish is that the following naïve ideas, offered to improve policy, will be of some help.

I avoided as much as possible technical expressions and bibliographic references. They do not serve but hinder the development of ideas and the flow of reasoning. Philosophy is conceptual design (Floridi 2019). At its best, it analyses fundamental problems-that is, those richer in consequences (like the first dominos in a chain)and articulate, in a factually correct and logically cogent way, solutions that are always open to sensible, informed, and urbane discussion, because the problems in philosophy are intrinsically open. Scholarly and rhetorical trappings unnecessarily burden it, hiding its rational and functional structure, and I have therefore tried to avoid them.

\section{The idea of a transition from things to relationships}

Our way of thinking-especially in economics, law, politics, and sociology-is still dominated by a profound and implicit philosophy of an Aristotelian and Newtonian nature, and it is now obsolete. In order to label it, we may conveniently refer to this "philosophy behind philosophy"-this conceptual paradigm that we do not question when we do philosophy-as our Ur-philosophy.

The Aristotelian and Newtonian Ur-philosophy has worked well in the past: our way of thinking is still unknowingly formatted by it precisely because of its great success. Let's see it briefly, to understand why it would be a mistake to continue to apply it (perhaps by adapting it), to try to extract from it the right answers to the new political questions posed by the information society.

An Aristotelian Ur-philosophy conceives of society as lego-like in structure. There are many units of bricks that connect to other units of bricks, from the bottom to the top, to create complex structures, interacting with each other. Bricks or atomic (i. e., not further divisible) entities are natural or legal persons. And their various combinations are the couple, the family, a generation, a social class, an ethnic group, an industrial sector, an administration, a political party, and so on. The properties (what qualifies the bricks for what they are, for example "age", or "is a company") and behaviours (what qualifies the bricks for what they do, for example "teaches at a high school", "manages sales in a shop") of bricks/persons combine in a more or less complex way. They thus give rise to inherited properties and behaviours. The assumption is that, for example, honest bricks/persons create an honest-emerging built society; or, with another example, unfairly advantaged 
bricks/persons create an unfairly built society. In more precise but technical terms, our Aristotelian Ur-philosophy, and the related sociological thought that is based on it, uncritically assumes an ontology formalized by "naive set theory". ${ }^{3}$ This considers a set (in our case the society) as a variously complex and differently structured collection of simple objects, called elements or members of the set. And it analyses all the other non-atomic "social objects" (family, generation, social class, party, trade union, etc.) in terms of sets of natural or legal persons.

To this Aristotelian Ur-philosophy of things one then needs to add a Newtonian conception of space-for example, the house, the city, the region, the territory, the nation, the country, the borders, the land, the sea, the sky-and of time-for example, the days, the months and the years, the history, the tradition, the recurrences, the deadlines, the holidays-understood as two rigid and absolute reference frameworks or containers (not related to anything else), which are dynamic only insofar as they tend to an ideal definitive stability. Imagine a large box, space, in which the persons-bricks interact, in a linear and irreversible way, along the arrow of time. The fascist concept of "living space" ("spazio vitale") and the Nazi concept of "Lebensraum" are ideological aberrations of this Newtonian Ur-philosophy of physical space as geographic territory and physical time as a calendar.

As a whole, our Aristotelian-Newtonian Ur-philosophy of things, time and space puts all the emphasis on the concept of action as the essential point (the ontological variable, we would say philosophically) on which to press constructively in order to modify or improve the behaviours or properties (nature) of the elements/persons themselves and, above all, of their structural combinations, and therefore of the society they constitute. To simplify: according to this vision, society changes by operating on the actions of the natural or juridical persons that constitute it. The actions are therefore the point of pressure of the system on which to intervene in order to be able to manage, drive, or modify a society. From this, there follows a vision of law as a system through which one shapes the actions of agents-bricks (and their compounds) in time and space.

The metaphors of society as a body, organism, or system, or that speak of coordination, cohesion etc. are all based on this Ur-philosophy. One finds it in Menenius Agrippa's Apologia and later in Paul of Tarsus' advice to the Corinthians, as well as in the first pages of Hobbes's Leviathan. And from Weber onwards, the emphasis of sociological theorising on the concept of action indicates how the design of social architecture is still concentrated today on forming and directing behaviours by focusing only on actions and their effects as the entry points for any policy.

The crowning of the Aristotelian-Newtonian paradigm in sociological thought is the idea of constructing the social mechanism: atomic entities in their own right, thanks to their properties and behaviours, are combined into a structure that has its properties and behaviours, like an analogue clock. The construction of the desired mechanism, for properties or behaviours (in our case, a society), starts from the identification of the necessary and sufficient components needed to make it happen.

\footnotetext{
${ }^{3}$ See for example (Halmos 2017). Axiomatic set theory analyses sets on the basis of the relation of satisfaction of specific axioms.
} 
If the mechanism does not work, or works in an unwanted manner, one may repair, modify, or add the responsible components, or the components that are necessary and sufficient for the solution, until they work as desired. The concept of "performance" and its quantitative analyses are the contemporary translation of this Aristotelian-Newtonian approach.

The Aristotelian-Newtonian paradigm has had its merits, but today it no longer responds to the needs of a mature information society, that is, a society whose members assume the digital as a foregone phenomenon (I will return to this concept later).

Since the twentieth century, the most formal and quantitative sciences-from mathematics to physics, to logic-confronted with more difficult conceptual challenges, have been forced to abandon the old Aristotelian-Newtonian Ur-philosophy or, if they still adopt it, they do so critically and with full awareness of its limits, essentially as a fall-back. Their "new" (but in fact now a century old) Ur-philosophy can be defined as relational. The problem is that our brain, our sensory apparatus, our languages and our Western cultures, by their nature, hypostatize (i. e. reify, or with a more intuitive term "thing-fy") the world, organizing it as lego: first there are things (nouns), then there are the properties of things (adjectives), and then behaviours of things (verbs). For example: Alice (what) writes (behaviour) with the blue pen (thing + property) on the white paper (what + property), and so on, for the rest of our experiential world. This is the way we are used to thinking. Our AristotelianNewtonian Ur-philosophy is so powerful because it is the codification of our deepest intuitions as intelligent mammals.

A relational Ur-philosophy uses sophisticated mathematical tools to overcome the obstacles of Aristotelian-Newtonian intuition and common sense in the various scientific fields. For example, relativity theory requires vector spaces, in which tensors are used to describe space and time in terms of four-dimensional spacetime. And category theory replaces set theory to uncouple the foundations of mathematics from the assumption of first elements understood as things, according to the Cartesian metaphor of the apples (elements) in the basket (together). The two examples are important, but they are also a bit disheartening. Because they are complicated and difficult. And if the request advanced in this article is to change the way we think politically, in the same way that we were forced to change our thinking on physics and mathematics, the suspicion that we are heading towards a resounding failure is justified. We can hardly understand how our democratic systems work. How can we therefore abandon such an intuitive and familiar Ur-philosophy in sociological reflection like the Aristotelian-Newtonian one, when we will have to dialogue with everyone (given no-one can exist outside of politics, as discussed), but without necessarily relying on a common conceptual vocabulary, especially when human reflection focuses on its conceptual and factual artefacts, such as society, economics, jurisprudence, and politics, which, by their nature, invite us to linger in a "natural" way of thinking? Society not only interprets itself in terms of "lego", it also builds itself in terms of "lego". Changing both trends seems a titanic effort destined to fail.

It must be admitted that the abandonment of an Aristotelian-Newtonian Ur-phi- 
losophy is a really difficult conceptual transformation, much more difficult than accepting that the earth is not flat, or at the centre of the universe, or that each of us is in large part a field of forces. The phenomena investigated-in our case, society and politics-impose a paradigm shift in a much less steady way (in terms of less intractable problems to be solved), and with much weaker standards (in terms of evaluation of the solutions). In other words, the Aristotelian-Newtonian Ur-philosophy is natural, intuitive, familiar, does not easily show its limits, and has worked in the past. The alternative is untested, counter-intuitive, unfamiliar, it is not how we conceptualise the world and our societies in it, or how we go about designing and constructing them, and does not really seem to be forced upon us by the nature of the problems with which we are dealing. It is going to be a hard selling.

An excellent example of this inability to think outside an Aristotelian-Newtonian paradigm is provided by Margaret Thatcher, not by chance an Oxford graduate in chemistry with a specialization in crystallography (few other scientific areas appear more Aristotelian-Newtonian). The "lego" model-which, I repeat, is now inadequate but difficult to replace-is evident in her famous interview from 1987:

[T] here is no such thing as society. There are individual men and women, and there are families. And no government can do anything except through people, and people must look to themselves first. It's our duty to look after ourselves and then, also to look after our neighbour. People have got the entitlements too much in mind, without the obligations, because there is no such thing as an entitlement unless someone has first met an obligation. ${ }^{4}$

Note the admission (for political rhetoric) that the family should be considered to be a basic element of society. In fact, it is contradictory: where does a family end? Do we include only parents and progeny, or even grandparents and aunts and uncles? And the cousins? And on what basis do we admit "the family" and not, for example, a group of families who are related to each other and represented by a village? And why not admit the whole human family? A dangerous slippery slope for any coherent thinker who is not also a politician.

The same (unsatisfactory) Aristotelian-Newtonian Ur-philosophy-this time stated almost literally, given the etymology of economics as regulation (nome) of the house (oikos)-is evident in Thatcher's simplistic conception of politics and the economy:

Any woman who understands the problems of running a home will be nearer to understanding the problems of running a country. ${ }^{5}$

Aristotle would have been happy with this statement. But we are not. Because today it is virtually impossible to understand accurately-and even more so, to manage successfully-in a simple framework of home government and ordinary Aristotelian-Newtonian insights, phenomena such as the purchase of their own shares ("buy-backs") by a company; a policy of negative interest rates (a tax on

\footnotetext{
${ }^{4}$ Interview 23 September 1987, cited in Douglas Keay, Woman's Own, 31 October 1987, pp. 8-10. https:// en.wikiquote.org/wiki/Margaret_Thatcher

${ }^{5}$ BBC (1979), cited John Blundell, Margaret Thatcher: A Portrait of the Iron Lady (2008), p. 193. https:// en.wikiquote.org/wiki/Margaret_Thatcher
} 
owning money, to use Gesell's expression), supported by an inflationary monetary policy; the popularity, in recent times, of negative-performing government bonds, such as those issued by Germany; the fact that austerity is better exercised when it is possible but unnecessary, that is, in moments of economic growth, and not when it seems necessary, that is, in moments of crisis, when it is damaging; the goodness of a minimum degree of inflation; or populist and self-destructive phenomena of democratic implosion, like Brexit, the Trump presidency, and the success of populist parties in the Italian elections of 2018.

Society is not lego, and politics or a nation's economy cannot be understood in terms of mere management of household affairs. Thatcher was wrong. It is as if the CERN wanted to use only Newtonian physics to understand the behaviour of subatomic particles. The point is not that Newtonian physics does not work, but that it no longer works in this case, and that this case is now the more fundamental one.

In order to cope with the new challenges posed by mature information societies, where well-being is higher and more widespread than in the past (and compared with other developing societies), and the degree of complexity and interconnections is now profound, political thought must take a step forward and update the common-sense intuitions espoused by the Aristotelian-Newtonian paradigm. But what concept can today replace the main one of a social thing?

Almost a century ago, Cassirer identified the end of what I have defined here as the Aristotelian-Newtonian paradigm in the transition from the centrality of the concept of substance (things) to the centrality of the concept of function (relations) in mathematics and physics (Cassirer 1923). He was right, and the next step is simple: a function is only a special kind of univocal relation between input and output. ${ }^{6}$ It is therefore a matter of appreciating the possibility that it is not the concept of "thing", but that of "relation"-which refers to what constitutes all things and connects them among themselves-that can play a foundational role in the political thought of the twenty-first century.

We saw the difficulties, but there are also good reasons to be optimistic about the conceptual feasibility of this paradigm update. The conceptual vocabulary of relations is sufficiently rich, semantically, to allow us to express everything we want to express in the political vocabulary of things, their properties, and their actions. In more precise terms, the concept of relations is powerful enough to define all the necessary ontology. ${ }^{7}$ This semantic equipotency makes possible something far more important than a mere translation exercise. It has the enormous advantage of mov-

\footnotetext{
${ }^{6}$ Here, "relation" is to be understood in the logico-mathematical sense, as anything that qualifies every thing-human, natural, artificial-individually (e.g. Alice is unmarried, which is a unary relation) or not individually (e.g. Alice and Bob are married, which is a binary relation; or Carol is sitting between Alice and Bob, which is a ternary relation; and so forth for any n-ary relation).

${ }^{7}$ All entities are reducible to bundles of properties, and all properties are reducible to n-ary relations, so all entities are reducible to the totality of bundles of relations. Behaviours and changes in properties of entities are then reducible to state transitions, and the latter are reducible to transitions from one set of relations to another. In short, one can use the vocabulary of relations to speak of entities, properties, actions, and behaviours-and that is all that is needed. Note that this is not a metaphysics, but a way of describing the world at a relational, instead of substantial, level of abstraction. That is, it is an epistemological ontology.
} 
ing and expanding (the dual movement is crucial) our focus first on the analysis and design of relations, rather than on the realization of specific actions or interactions, as the main point of pressure on which to operate to try to improve a society in a lasting and not ephemeral way. In simple terms: economics, jurisprudence, sociology, and above all, in our case, politics, become relational sciences of the links that make up and connect the relata (not just people, but all things, natural and constructed, and therefore their environments and ecosystems), even before being behavioural sciences studying the nature and actions of those special entities (that are natural and legal persons understood as things). In this, Hegel and Marx were perhaps prescient when they put the accent not on people themselves, but on the dialectical relationships between people.

This shift in conceptual paradigm changes the implicit operating model, which is no longer that of the Aristotelian-Newtonian mechanism, rather rigid and restrictive, but that of the force field or relational network, much more flexible, inclusive, and unbounded. In a network, nodes (including all people, but not only) do not preexist to be connected by relations, as is the case for the lego bricks or the components of a mechanism. Rather, they are the relations that make up the nodes, in the same sense in which the roads constitute the roundabouts. Therefore, if the properties or behaviours of the nodes-entities can be improved, it is on the nature and the number of the relations that constitute them that we must intervene. The new model, placing the relations at the centre of the socio-political debate, is more easily able to include in its analysis all the entities (relata), not only persons, but also the world of institutions, artefacts, and nature.

We know that things are discrete and can easily be grouped in separate sets. For example, we can group the set of all Italian citizens, the set of all French citizens, and the set of all citizens with both nationalities. Venn diagrams are popular for this reason. But social relations tend to be intertwined and continuous, with varying degrees of intensity, from weak to strong. In our example, we may be better off by speaking of Italian citizens who have relations with French citizens and vice versa in a variety of ways, i.e. relations that are more or less intensive, superficial, fruitful, frequent etc. As a consequence, in a "relation-oriented" and not "thing-oriented" policy, it is no longer the quantifiable amount of "performance" of things that is the main parameter of evaluation, but the degree of solidity and resilience of the relations that constitute things and bind them together, citizens included. When today we observe that, in some European countries, for example, the financial and political crisis has been addressed thanks to the efforts of families or social institutions, what we are actually saying, looking more carefully, is that it is the social network that today is making possible and less traumatic the transition from an industrial country (production of things and quality of things) to a country with a green and blue digital economy (production of services-functions and quality of experiences). This is not at all to contradict the phenomenon of globalization. On the contrary, a relational and not "substantial" (thing-oriented) view of society explains the current tendency of politics to become global and cosmopolitan, more based on diplomacy (a coming together of relations) than on war (a clash of things) according to a reticular philosophy. 
This paradigm shift, which has been necessary since the rise of information societies, implies the abandonment not only of an Aristotelian ontology of the primacy of things, but also of a Newtonian ontology of space and time as rigid containers, within which things are positioned, move, interact, and change. Let's see how.

A network is a logical space, not a physical one, in which distances are measured with metrics that are not Euclidean. With an elementary example: in chess, the distance between a pawn and the queen is symmetrical in the Euclidean sense, for example 10 centimetres from the pawn to the queen and therefore from the queen to the pawn. However, it is asymmetric in the logical sense, for example a step from the queen to the pawn, but three steps from the pawn to the queen. Still in chess, the diagonal is necessarily longer than the column from a Euclidean point of view, but on the chessboard it has the same length in terms of number of squares, and therefore the king takes the same number of steps in covering both. In our case, with the arrival of the Internet, the space of politics (a relational and therefore logical space) no longer overlaps, indistinguishably, with the space of geography (a "substantial" and therefore physical space) of national sovereignty. This has been the case for a long time, since the old Westphalian identification of legal space with political space. On the contrary, the space of politics becomes the spatiality of social relations, including those of strength. The old concept of a "zone of influence" already anticipates this idea in part. For example, the Mediterranean nature of Italy is above all cultural (i.e. relational), not merely geographical; likewise, Denmark is a Scandinavian country; and Spain can be as Mediterranean as Greece. This is why the EU should allow the expulsion of European member countries that do not respect agreements and shared values, and drop the geographical clause that prevents a non-European State from joining the European Union. ${ }^{8}$ More Europe also means having the courage to abandon the twentieth-century geographical space, on which the EU was founded, to adopt a relational spatiality, making possible the exclusion of European countries that repeatedly deny the values of the EU, because geography is no longer sufficient, and the inclusion among its members also of countries not belonging to the continent, but which respect and promote its values, because geography is no longer necessary. From this new perspective it would be very reasonable to think of Canada, for example as a possible member of the EU, as has already been done in the past. ${ }^{9}$ If this relational approach seems counterintuitive, consider that it was already adopted with Cyprus, a State that, in terms of Newtonian space, geographically belongs to Asia, but which rightly entered the EU in 2004 on the basis of a spatiality made of historical-cultural relationships.

Similarly, political time takes care of the temporality of relations. For example, something becomes possible only after something else has happened: a concrete

\footnotetext{
${ }^{8}$ Article 49 (formerly Article 0) of the Treaty on European Union, or Maastricht Treaty, states that any European country that respects the principles of the EU may apply to join. A country classifies as European "subject to political assessment" by the European Commission and more importantly-the European Council. This geographic membership criterion was later enshrined in the so-called Copenhagen criteria.

9 See https://mowatcentre.ca/canada-should-join-the-eu-sort-of/
} 
discussion of the feasibility of Eurobonds is conceivable only after the approval of the German government, in terms of the logic of chronological relations (before, during, after), and not of calendar year or calendar (absolute dates and times). And intergenerational relations are no longer relations between lego-like AristotelianNewtonian persons, but relational ties between node-like persons, something the vocabulary of politics describes as "social fabric", a crucial concept on which we need to pause for a moment.

To introduce this idea, it is useful to start from another version of the quotation from Thatcher we have already seen, on the sole existence of individuals and the non-existence of society:

A transcript of the interview at the Margaret Thatcher Foundation website differs in several particulars, but not in substance. The magazine transposed the statement in bold, often quoted out of context, from a later portion of Thatcher's remarks: "There is no such thing as society. There is living tapestry of men and women and people and the beauty of that tapestry and the quality of our lives will depend upon how much each of us is prepared to take responsibility for ourselves and each of us prepared to turn round and help by our own efforts those who are unfortunate". ${ }^{10}$

In a tapestry the fabric is woven in blocks of coloured weft threads, which are beaten down very tightly on the warp threads, producing a picture or pattern. When the work is finished, the warp threads are hidden. Weft and warp are sets of threads. Each thread is individual and the figures in the tapestry (and the tapestry itself) emerge from their intertwining. So, Thatcher was right in the choice of her conclusion: her likening of the "social fabric" to a tapestry is correct, if one looks at the internal coherence of her ideas. But a fabric does not necessarily have to be "woven" like a tapestry, it can also be knitted (a word that comes from "knot", which clearly relates to network), like a blanket. And in this case, it is a fabric formed by a number of consecutive rows of intermeshing loops. The loops do not pre-exist the fabric, but co-exist with it because of the common thread. Thus, Thatcher was wrong in choosing the premise: because the social fabric is a lot like a knitted blanket, not so much like a woven tapestry. It is not a new idea (Blondell 2005), politics as weaving a society together is already present in Plato's Statesman (308-311) and in Aristophanes' Lysistrata (565-86):

Till from the vast heap where all is piled together at last can be woven [ن́ $\varphi \tilde{\eta} v \alpha \iota]^{11}$ a strong Cloak of State.

Finally, the personal fabric is the "inter-temporality" of an individual life, that is to say, the fact that human existence, individual and social, is like a knitted thread, whose loops must relate correctly with each other according to a coherent design. For example, if one invests in higher education one should then find a place in society to work. There must be inter-temporal links that give meaning to paths, trajectories, expectations, individual and social human projects (more on this later),

\footnotetext{
${ }_{10}$ See https://en.wikiquote.org/wiki/Margaret_Thatcher

${ }^{11}$ From ú $\varphi \alpha i v \omega$ meaning not only to weave a web, but also metaphorically to create, to construct, hence to contrive and to plan.
} 
and so on. Politics must know how to take charge of the "inter-temporality" of people's lives and of the intrinsic relationships and connections between the phases of human existence, addressing not only individuals' interests but also their hopes, by means of a human project, as we shall see next.

\section{The idea of a human project}

By "human project" I mean the kind of life and society we would like to achieve. In a more simplistic way, it is what political parties, often without critical conscience, try to summarize in their electoral slogans, for example "For the many not the few" (British Labour Party, 2017), or "Building a country that works for everyone" (British Conservative Party, 2017). In a more analytical way, the human project is the form of human life-programmatic in its various individual, collective, private, and public manifestations-that a society presents and promotes from time to time as desirable, at least in theory or implicitly, and depending on historical moments.

Perhaps a close, philosophical term to describe the concept of human project is the Wittgensteinian term of humanity's social Lebensform, but the concept of human project is not just descriptive is also normative, in the Kantian sense of regulatory ideal. It is plausible that each human project, at every stage in human history, is not entirely feasible, or is only minimally feasible, and therefore should be understood only as a goal. Despite this limitation, two crucial observations remain correct.

First, each society incorporates its own human project, no matter whether this is only implicitly or explicitly pursued, whether it is coherent or contradictory (for example, when it comes to promoting several projects that cannot be reconciled with one another), pragmatic, realistic, or utopian. This happens for two reasons. Because individuals get together, voluntarily or not, on the basis of a shared purpose-the human project-be this positive (as in Plato or Rousseau), in order to achieve a higher degree of trust, coordination, and collaboration; or negative (as in Hobbes or Kant), in order to achieve a lower degree of distrust, conflict, and insecurity. The second reason is because the very absence of a human project is itself a project. We are back to the relational nature of phenomena that also absorb their negations. Not having a project does not mean you are doing without one, but rather that you have opted for a bad project, underdeveloped and uncontrolled. It follows that a society without a human project does not exist. There are only societies with human projects that are more or less good, achievable, or compatible with each other.

Second, although every society usually tends to absolutise its human project as unique (there is only one, its own), eternal (its own is always valid) and universal (its own is valid everywhere), in reality there is no single human project, but as many human projects as there are societies, states of societal evolution, and historical circumstances in which they are found. This pluralism is not relativism, as if one were saying that every human project is necessarily as good or bad as any other. In 
reality, it is a matter of adopting a serious and relational way of describing the plurality of the projects in question, as made possible also by what has already been achieved, and therefore known, and by what has not been realized, but it is conceivably achievable. The human project described by Cicero in De Republica is very different from the one described by Tocqueville in De La Démocratie en Amérique, and neither is easily applicable today to the information society.

Among the various factors that explain the sense of radical transformation and uncertainty characterizing our time there is, above all, the implicit perception of the absence of a human project in the information societies that are maturing before our eyes. The metaphor is that of ever-faster traveling in a still unknown and sometimes obscure direction. The problem is exacerbated by the fact that we do not have a human project for the digital age (to be precise: we obviously have a project - as absence of project is itself a project - it is just not planned). However, we do have a postmodern starting point, in the sense of an incomplete meta-project shared by the industrial and post-industrial consumer society, which today characterizes many advanced economies. The old project is dying but the new project struggles to come to life, to paraphrase Gramsci. Both terms, "meta-project" and "incomplete", need to be clarified.

The postmodern meta-project consists in the fact that the information society, like the consumer society, pursues the human project to make the various individual human projects possible and compatible with each other. In other words, in the best of cases, today the human project is reduced to the support of individual projects (aspirations, hopes, plans etc.), that is, to the social project to make the various individual projects feasible and compatible with each other. To exemplify, we do not pursue a "happy society", but rather a society in which every individual has the opportunity to pursue his or her own happiness, provided this is not at the expense of others. The examples can be multiplied: we do not pursue a rich society, but a society in which every individual has the opportunity to get rich within the limits of legality; not a healthy society, but a society in which every individual has the opportunity to live and take care of him or herself in a healthy way within the available constraints; and so on.

The meta-project is clearly liberal. The purpose of the State is centred in defending and promoting the rights of each member of society, in a mutually compatible way. And the mechanism on which this relies is that of the "spontaneous" emergence of the desired social-relational properties, starting from the realization of the individual relations that are supported. It is an approach still based on the "lego" model we already encountered. In the previous example, allegedly, a happy society would spontaneously emerge from the happiness of its members. Economically, this emergentism goes well with liberalism: the State ensures a free market in which individuals can own, produce, and trade economically, within the limits of legal compatibility. In some cases, ethical liberalism and economic liberalism end up supporting political libertarianism, which promotes the maximum reduction of the functions of the State in favour of the freedom and responsibility of individuals.

The liberal and postmodern meta-project is incomplete because it focuses only on the interests and hopes of the individual, or at most of the person, including the 
legal person (think of corporate taxation), but does not provide, nor does it mean to provide, programmatically, an indicative framework on the kind of society that one would like to build together, and for which coordination of the efforts of many, if not all, is needed. I will return to this second point in the next section. Here it is worth stressing that, in the past, starting from the twentieth century, the incompleteness of the postmodern meta-project was made less evident by the great historical disasters of the two World Wars and by the ensuing reconstructions, by the Cold War, and by political and religious ideologies. Whenever we had to fight together against something for something-for better or for worse-or to build or rebuild together what we inherited from this fight, or whenever we adopted a collective ideological or religious faith, in all these and similar cases the postmodern metaproject was supported externally, by other social or community projects, which hid its incompleteness. The great movements for various human rights, the pacifist and ecological movements, for example, have provided the social component to the postmodern human project, which otherwise would long have remained limping on the single leg of the individual human meta-project. In the best of cases, these external social projects have been "included" in the human project, providing it with the non-individualistic component. Think of the work of Martin Luther King in the United States, the fall of the Berlin Wall and the reunification of Germany, or the end of Apartheid in South Africa. The same happened for political and religious ideologies. Fundamentalism and populism are also answers addressing, implicitly and uncritically, the incompleteness of the current human project.

Today, the gap between social projects and political projects is extreme, and the former can no longer hide the incompleteness of the latter (using a British example, Cameron's "Big Society", with volunteering replacing government services while hiding a paucity of political ideas, did not last long and was a failure). The social project, whatever it is, is no longer part of the political project. Quite the opposite, it often distances itself from the political project in an anti-political way, falling into the negative dialectic described in the introduction. The proof is that the world of volunteering and therefore social commitment grows together with disenchantment for political commitment, and its refusal. For example, according to the latest ISTAT data, in 2013 in Italy 6.63 million people (12.6\% of the population) volunteered their time and work for free and for the common good. In the light of what I have argued, this is not a contradiction, but a consequence of an incomplete human project: politics has not taken on a social human project, and this need, which goes beyond individual human projects, is otherwise met, outside of politics.

This generates three risks. We have already discussed the first one. Community activism, detaching itself from the human project, risks leaving it unlimbed and limping. The second is the double illusion that community activism can somehow compensate for the absence of a social human project-as opposed to an individual human project-and that politics can not only be left limping but continue so without any negative consequences. The third is that community activism is confused with the social human project and tries to replace it, through movements that claim to be political, but do not intend to do politics positively, because they fail to recognise that good politics is the properly regulated evolution of community cooperation. 
All this leads to a crucial question, which is essential if we are even to hope to be able to outline a good human project for a mature information society: if it is possible to adopt not only an individual meta-project, but also a social project-and this conditional is not rhetorical at all-is it possible to do so today without falling into a right-wing or left-wing ideology, or a religious one? In other words, is a complete human project possible, both as a meta-project for the individual and as a social project, that is neither ideological nor transcendent? I believe the answer can be positive, but the room for manoeuvre is narrow. Let's examine it.

It is indicative that one never speaks of a centrist ideology. The centre of politics does not have its own ideology because, in the best of cases, it transcends the latter, adopting ethics as the main and superior guide. And in ethics-from Aristotle to Rawls-the end is always that of equilibrium and of a collaborative reconciliation of interests, rather than the imbalance of the confrontation of parts, in a zero-sum game. The centre does not promote or lead "political struggle", but creates political convergence; connects, does not disconnect; it does not quarrel, it argues. For this reason, the human project that we can hope to draw today can proceed socially and not only individualistically (and hence only metaprojectually), if it is pursued in an ethical-centric way, and not in an ideological way of left or right; and in an immanent and not transcendent way, staying within history and improving it from within, not coming out of it in a saving way, and rejecting it. That is to say that good politics will no longer take left vs. right seriously, but will concentrate on centrist alternatives that have more or less successful strategies to approach the human project. To be coherent, the ethics to be adopted will have to be inclusive of all those parts of the world and society inevitably ignored by the meta-project, that is, those parts that do not play an active role in presenting and managing their own interests and rights in the first person. It is one of the great lessons that political commitment can learn from the community commitment: the human project for the digital age and for a mature information society must include the "silent world": the marginalized, the disadvantaged, the weak, the oppressed, the past generations to be respected, and the future ones to be facilitated, the environment (natural and artificial), and that semantic capital formed by culture and memory. In other words, it must be an ethics of the interests of all the "patient" nodes (those who receive the effects of political action), and of the various networks that they form, and not only of the individual "agent" nodes, whose interests are already taken care of by the meta-project component, which knows their requests because they are presented explicitly and constantly. It will have to listen to those who are not heard by the meta-project.

As for the relationship with religion, the human project must support a secular and immanent society, while being fully respectful of the faiths that can not only cohabit but also flourish within it. The reasons in favour of a lay human project are many. Only a secular society can be coherent with the meta-project, which, to repeat, is a project to facilitate individual projects to the extent that they are mutually compatible. Only a secular society can be truly tolerant, that is, sincerely respectful and supportive of the great variety of individual human projects. And only a secular society can lack any interest in proselytism, and not fall into the temptation of 
imposing a specific vision (religious or otherwise) of the human project at the expense of other visions, or a specific evaluation of the world as comprising "we" and "they" (religious divide). The human project will need to be secular and lay because ethics can unite and support faith, but faith often ends up dividing and defeating ethics.

To sum up, the human project for a mature information society must first be ethical and then be political, and it will have to be made up of two components, one now classical, represented by the liberal meta-project that favours individual projects, and the other still to be built, which can also make social sense of the way we live together, as a community. The fact that today there is no serious utopian thinking shows that we have not yet developed the second part. To fill this gap, we need an important thing: a good ethical infrastructure that allows coordination and care of the social fabric. This is the topic discussed in the next section.

\section{The idea of an infraethics}

It is a sign of our times that, when politicians speak of infrastructure nowadays, they often have in mind information and communication technologies (ICTs). They are not wrong. And it is an old story. From success in business to cyber-conflicts, what makes contemporary societies work depends increasingly on bits rather than atoms. Depending on their digital infrastructures, societies may grow and prosper. And it is ICTs that can also present a catastrophic weakness, in terms of cyber security and the vulnerability of our increasingly networked critical infrastructure. We know all this. What is less obvious, and philosophically more interesting, is that ICTs also seem to have unveiled a new sort of equation.

Consider the unprecedented emphasis that ICTs place on crucial phenomena such as accountability, intellectual property rights, neutrality, openness, privacy, transparency, and trust. These are probably better understood in terms of a platform or infrastructure of social norms, expectations and rules, that is there to facilitate or hinder the moral or immoral behaviour of the agents involved. By placing at the core of our life our informational interactions so significantly, ICTs have uncovered something that, of course, has always been there, but less visibly so in the past: the fact that moral behaviour is also a matter of "ethical infrastructure", or what I will simply call infraethics.

The idea of an infraethics is simple, but the following "new equation" may help to clarify it further. In the same way as business and administration systems, in economically mature societies, increasingly require physical infrastructures (transport, communication, services etc.) to succeed, likewise human interactions, in informationally mature societies, increasingly require an infraethics to flourish. The equation is a bit more than just an analogy between infrastructure and infraethics. When economists and political scientists speak of a "failed state", they may refer to the failure of a state-as-a-structure to fulfil its basic roles, such as exercising control over its borders, collecting taxes, enforcing laws, administering justice, providing schooling, and so forth. Or they may refer to the collapse of a state-as-an-infra- 
structure or environment, which makes possible and fosters the right sort of social interactions. This means that they may be referring to the collapse of a substratum of default, accepted ways of living together in terms of economic, political and social conditions, such as the rule of law, respect for civil rights, a sense of political community, civilised dialogue among differently-minded people, ways to reach peaceful resolutions of tensions, and so forth. All these expectations, attitudes, rules, norms, practices-in short, such an implicit "socio-political infrastructure", which one may take for granted-provides a vital ingredient for the success of any complex society. It plays a vital role in human interactions, comparable to the one that we are now accustomed to attributing to physical infrastructures in economics.

The idea of an infraethics can be misleading, because, despite the economic analogy, an infraethics should not be understood in terms of Marxist theory, as if it were a mere update of the old "base and superstructure" idea. The elements in question are entirely different: we are dealing with moral or immoral actions and notyet-ethical facilitators of such moral or immoral actions. Nor should infraethics be understood, conceptually, in terms of a kind of second-order or metaethical discourse about ethics, because it is rather the not-yet-ethical framework that can facilitate or hinder evaluations, decisions, actions, or situations, which are then moral or immoral. At the same time, it would also be wrong to think that an infraethics is either ethically neutral or simply has an ethical dual-use, because its dualuse is always oriented. If it were just neutral, this would mean that an infraethics would not affect either ethical or unethical behaviour, a mere logical possibility that is utterly unrealistic. In philosophy of technology, it is now commonly agreed that design-in any context, society included-is never ethically neutral, but always embeds some values, whether implicitly or implicitly. Yet this does not mean that an infraethics is simply dual-use, as if it could both facilitate and hinder morally good as well as evil behaviour in equal degree, depending on other external factors. The textbook example is the knife that can save a life or murder someone. And the trivial comment is that its use and hence moral evaluation depends on the circumstances. This is true, but insufficiently perceptive. Because not all knives are born equal. The very short, blunt, round knife that an airline provides to spread butter has a dual-use that is hugely oriented to fulfil a purpose that the butcher's knife can also fulfil, but much less easily. A bayonet has a dual-use only theoretically, because it is designed to kill a human being, not to cut bread. Likewise, every infraethics may be dual-use only in principle: in fact, if it is a good infraethics, it means that is oriented towards facilitating the occurrence of what is morally good. At its best, an infraethics is the grease that lubricates the moral mechanism in the right way and successfully. So, it is easy to mistake the infraethical for the ethical because, whatever helps goodness to flourish or evil to take root, it partakes of their nature.

As I mentioned in the previous section, speaking of the need for a human project that is not only meta-conceptual but also social, every society-be this the City of Man or the City of God, to put it in Augustinian terms-pursues its human project (even if only unconsciously) by adopting (even if only implicit) an infraethics, which can be more or less morally successful, and more or less evil-unfriendly. It follows that even an ideal society of angels, that is, a society whose nodes are all 
impeccably good moral agents, needs infraethical rules for coordination and collaboration. In other words, not even a society of angels can succeed if it is exclusively a libertarian one. It too needs a social project to support its development. Thus, James Madison was partly (more on this specification below) mistaken when he famously wrote that

If men were angels, no government would be necessary (The Federalist No. 51, 1788).

He was partly mistaken because he had a merely negative anthropology in mindthe one so well-articulated by Thomas Hobbes in his Leviathan and De Cive ("homo homini lupus") and never revised nor criticised by John Locke-and an atomistic view of society as a mere aggregate of individuals (recall the Aristotelian-Newtonian Ur-philosophy). Yet even a society of angels would still need some form of government, and hence an infraethics, to coordinate its good deeds, set common goals, evaluate the degree of success in pursuing them, and rectify the course of actions as a group, if necessary. Because "good" can always be "better" and "we the people" is not equivalent to a mere aggregate of all the Alices and Bobs in the world. An arch is not only a pile of stones. There is a moral goodness that is entirely social and does not emerge merely from individual moral goodness. Because goodness is also a matter of ambitious agency: what "we the people" can do and hope to achieve together, as opposed to what Alice and Bob could ever do individually. Angels would still need an infraethics to organise a party, or to push-start a car. It is not always true that every little effort helps: an angel attempting to push the car on its own will only waste its time and effort, completely. A multi-agent systemmany angels working together to push the car successfully-needs coordination and control if it is to achieve anything. We should also regard evil as a matter of opportunity costs (not just bad deeds), that is, what could have been done that wasn't. Without a system of governance, the angels will miss performing many good deeds that are only available to them as a group. This cost can be very high and morally negative in any society.

I specified above that I take Madison to be only "partly" mistaken about his positive assessment of angels as requiring no governance because that sentence should be read within its context, which states that

If men were angels, no government would be necessary. If angels were to govern men, neither external nor internal controls on government would be necessary (The Federalist No. 51, 1788, my italics).

The part in italics shows that Madison was actually referring to the need to structure the government with checks and balances (that is, with external and internal controls). So, one may read him more charitably, not as saying that any government, or any infraethics, would be unnecessary-as stated in the first sentence-but rather as saying that one designed on the basis of an angelic anthropology would be. That is, he might be interpreted as arguing not that rules for coordination would be unnecessary, but that special constrains on the application of these rules would be unnecessary if we were angels, because those governing and those governed would behave according to the proper application of the rules all the time. With an 
analogy, he might be read as saying that, if all men were angels we would still need driving rules to coordinate driving behaviours, but no police to enforce them.

Insofar as Madison was mistaken-the first sentence of the quotation above definitely is, and it is often interpreted by itself as meaning what I took it to mean above, as if every law and social regulation were based only on the dialectic between "crime and punishment"-it would also be wrong to dismiss the crucial importance of an infraethics not only from a libertarian but also from an anarchist perspective. In this case, the reasoning shares the premises and draws a different conclusion: if men were angels they would need no government, but men (sometimes) are angels, and so (sometimes) they do not need government. The spontaneous emergence of the morally good is therefore (erroneously) assumed as both natural and uncontroversial by libertarian and anarchist alike. Yet the truth is that without an infraethics to begin with (i.e. internal controls), and then the issuing of good governance that supports it (i. e. external controls), not enough moral goodness could ever be achieved individually. A multiagent system like a whole society needs its own organisation and governance, precisely because it is not an old Aristotelian-Newtonian cuckoo clock.

If we now return to the oriented dual-use of an infraethics, one may argue that a society of Nazi fanatics could rely on high levels of trust, respect, reliability, loyalty, privacy, transparency, and even freedom of expression, openness, and fair competition, without being for this any less evil. Clearly, what we want is not just a successful framework of facilitations and constraints provided by the right infraethics, but also a coordinated cohesion between them and morally good values, such as human and civil rights. This is why a balance between security and privacy, for example, is so difficult to achieve, unless we clarify first whether we are dealing with a tension within ethics (security and privacy as moral rights, i. e., both understood as "water" in the earlier analogy), within infraethics (both are understood as not-yet-ethical facilitators, i. e. as part of the pipework), or between infraethics (security intended as facilitator or "pipe") and ethics (privacy intended as a value, or "water"), as I suspect to be the case.

The right sort of infraethics is there to support the right sort of values (that is, axiology). Designing it, maintaining it and keeping it updated is one of the crucial challenges for our information society. It is also one of the reasons why, in terms of innovation, our age is the age of design, even more than an age of discoveries or inventions. Clearly, when politicians talk about "infrastructure" nowadays, they often have to deal not so much with bits and atoms, but rather with the infraethics and the values it supports. It is mainly working on these last two factors that politics can best support the right human project at the right time-for a mature information society.

\section{Ideas for a mature information society}

We have seen that political thought should move from a "substantial" to a "relational" approach, from mechanisms to networks. This means thinking of politics as 
a science of relations and as a guide and management of the ratio publica (more on this later) even before the res publica. The new relational paradigm helps us to understand how an information society, which is mature in terms of its socio-cultural expectations, can articulate and pursue its own complete human project-that is, both an individual human project as a meta-project for individual projects, and a social human project, for group projects-using the right infraethics to organise itself and realise it. All this makes possible, and at the same time requires, good ideas for a better politics. This is both in the sense of positive conditions of possibility, which aim to draw and then build what is or should be a good democracy for a mature information society, but also in the sense of negative conditions of possibility, which reveal the presence of bad politics, which hinders the construction of what is or should be a good democracy.

In this section, I present some of these ideas, those that today seem to me to be the most important. They can be read as conceptual explanations or logical consequences of a single premise: what a good politics for a mature information society is-that is, a politics that intends to pursue a complete and ethically desirable human project, through an effective and sharable infraethics.

I have tried to facilitate the task of the reader by schematically separating the various ideas and numbering them, so that it may be easier to agree or disagree with each of them. I have italicized some key concepts when they are introduced for the first time before being discussed or explained. And I tried to make the text readable on two levels. The first level is a network that simply connects every numbered idea, readable as a node, while ignoring the paragraphs below, which represents a further analysis. For those in a hurry, it should be enough to read just the numbered phrases. For those who have time and patience, the second level is more in-depth and sequential, and requires a non-reticular reading.

1. A society is the totality of the relations that constitute it. ${ }^{12}$

This is because a society is a network formed, and not merely composed, by many individuals, who are not like stones collected in a pile, but who interact, coordinate, and change.

2. A good society is a tolerant and just, and therefore peaceful and free, society. These four moral values, presented in order of logical precedence, are essential. They refer to the four conditions identified by Locke (tolerance is the foundation of peace), by Mill (tolerance is the foundation of freedom) and, between the two, by Kant (justice is the foundation of tolerance). However, in this article I argued that tolerance and justice have this logical order (tolerance has priority over justice), even if they are co-necessary. ${ }^{13}$

3. A civil society is organized into a political community, called a polity.

4. A government is the executive guide of the polity.

\footnotetext{
12 The implicit reference to proposition 1.1 of Wittgenstein's Tractatus ("The world is the totality of facts, not of things.") is meant.

13 See also (Floridi 2016, 2015).
} 
5. Governance is the activity of the government.

Governance includes the design and management of social policies, with proper oversight, transparency, and accountability.

6. Democracy is the best way to create and maintain the governance of a polity. This is because democracy maximizes the just care and tolerant flourishing of individual, social, and environmental relations, paying attention to the satisfaction of the interests, needs, and reasonable hopes of not only all persons (both physical and legal) but of all related "things", that is, the human, natural, and artificial relata.

7. The best form of democracy is representative.

This is because a necessary condition of democracy is the structural separation between popular sovereignty (those entitled to vote hold political power and can legitimately delegate it) and political governance (those who rule receive political power and can legitimately, transparently, and accountably exercise it, through revocable delegation). From this it follows that all forms of dictatorship-including that of the majority-spring from the self-legitimizing merging of sovereignty and governance, that is, between the possession and the exercise of political power. Every form of government and governance is fallible: sometimes they do not work, or they work badly. From this it follows that a representative democracy is preferable to a dictatorship not because it works better, but because it is much more resilient: when it does not work, it works much less badly than a dictatorship because it causes less damage and admits of change and repair.

8. Good democracy allows voters to choose between real alternatives.

This means that the multiplication or superfetation of choices and the lack of real alternatives of content is a hallmark of any anti-democracy in any political regime. It reduces the space of political decision: voters choose between options (as in a restaurant menu), but do not decide between alternatives (which restaurant to go to).

9. Good democracy offers the right granularity of alternatives.

This means that the more we collect packages of choices (bundles) in individual blocks on which to ask to decide politically, the less good the democracy in question is. This is an argument in favour of a mixed electoral system, with some balance between majoritarian and proportional features, to reach the right level of granularity.

10. A good society requires a good politics.

11. Politics is bad when it does not allow change to an individual's starting position.

The impossibility of modifying one's starting position constitutes another hallmark of the anti-democracy of a political regime, and it is equivalent to the reduction of space in the construction of the human project. Social mobility, for example, is a sign of good politics.

12. Politics is good when it seeks to take care of the prosperity of the whole society, of all the people who belong to it, and of public and common goods, including natural and artificial environments, which belong to it or in which it lives. 
"All" here means, ideally, not only the society that expresses it, but the entire human society, the whole network.

13. Prosperity is a relation that includes the protection and promotion of civil liberties, education, security, wellbeing, and equal opportunities. Following a relational and not "substantial" approach, arguing that good politics takes care of the prosperity of the whole society, of all the people who belong to it, and of public and common goods (including natural and artificial environments), means ensuring that politics is reticular.

14. The ratio publica is the totality of public, individual personal fabrics, the social fabric and the fabric of public and common goods.

15. Good politics is reticular (fabric-like), as it takes care of the interconnectedness of all nodes and relations (ratio publica).

16. Politics is bad when it tears the fabric of the ratio publica, failing to ensure a minimum level of decent life, individually and socially. For this reason, the violation of the dignity of the person or of groups of people constitutes another hallmark of the anti-democracy of a political regime, reducing the space within which one may flourish in a society.

17. Good politics is universally participatory.

Good politics requires the input and active participation of all the components of a society, including industry associations, companies, and administrative structures. Good politics is successful only if there is the involvement of all the stakeholders, at all stages, from the initial brain storming and reflection, to the development of good ideas, to their discussion and implementation. Participation has no natural boundaries, but only pragmatic limits. This is why good politics is also inevitably cosmopolitan.

18. Good politics can be transformed into good governance only thanks to the positive support of the public administration. Failing to work in synergy with the public administration is not only a strategic mistake, because the public administration knows the mechanisms and degrees of feasibility of political projects from within, it is also a mistake of perspective, because only the commitment of the public administration can guarantee the continuity and the final success of the projects even across several governments.

19. Implementing good politics together with the social partners and the public administration means drawing the basic relational mechanisms that facilitate the desired behaviours and hinder the unwanted ones.

This means working with policies "by design", which give shape to the conditions of possibility of behaviours that one wants to determine or modify. Designing such conditions means creating relational mechanisms that work not merely according to a logic of control and of possible sanctions, but above all according to a logic of reflexivity of self-reinforcement: virtuous circles such that the more they work, the better they work. For example, the widespread interest of citizens in the use of digital payments instead of cash can result, as a beneficial side effect, in greater tax control on the transactions themselves and therefore on tax evasion, a decrease of which could lead to a reduction in the tax burden, an improvement in the economy and greater incentive to use 
digital payments, and so on. It is therefore a question of technically designing virtuous circles that improve society and which are strengthened the more they are used.

20. Good politics pursues its aims, including its human project, through the promotion of economic well-being, freely enjoyed or sought by people, not through the exercise of coercion.

21. Good politics does not use coercion as a means but, classically, maintains its monopoly on violence to eradicate it altogether, or replace it with peaceful, equitable, sustainable, and productive competition.

22. Good politics is guided by good ideas in satisfying, reconciling, and prioritizing, within its human project, the reasonable hopes and legitimate interests of people and society, with regard to individual, social, and environmental prosperity.

23. Ideas are good when they provide politics with strategies that are feasible (achievability), efficient (cost), effective (result), shareable (consensus), and desirable (ethics) to take care of individual, social, and environmental prosperity.

24. Good ideas are generated by good reflection and are consolidated by good practice.

25. Reflection is good when it is rational in its reasoning, informed about facts, aware of its fallibility, tolerant of different opinions, and open to constructive dialogue.

26. Reflection takes place in the public sphere.

27. The public sphere is part of the infosphere.

28. A practice is good when it is transparent in the sense that is both accountable and auditable.

29. A good reflection is promoted by a good political debate.

30. A political debate is good when it is based on a good reflection and decides, in a satisfactory way, on the goodness of the available ideas, on their compatibility and priorities, and on how to achieve them, creating a fair and open market of tolerant and just ideas.

31. Good ideas are not partisan but, because of their nature, they are shareable by more than one political program.

Knowing how to recognize and support good ideas, regardless of the source and the context that offers them, is essential in a political context that is increasingly "on demand" and "just in time" and less and less "always on", in which the management of the attention of the civil society must be based on the forward-looking interest in the proposing of good and relevant ideas, and not on alarmism, emergency, or recurrent crises.

32. Sharing good ideas regardless of line-ups or political programmes means privileging ethics to ideology.

33. Good ideas motivate politically (in a sort of political psychagogy ${ }^{14}$ ) by relying on three factors: hope (which can also be altruistic and public, and when negative can become envy), interest (which is usually only personal and private, and

\footnotetext{
${ }^{14}$ In ancient Greek philosophy and early Christian theology the term refers to "guiding the soul", e.g.
} 
when frustrated can become anger), and (inclusive disjunction) reasonableness (from common sense to logic, from the correct use of facts to probabilistic reasoning).

34. Hope motivates more than interest.

There is no personal interest-including the fundamental one for one's own well-being or that of others, and for one's own survival or that of others-that cannot be overcome by hope, to the point that people can commit suicide because of their hopes. For this reason, fundamentalist or ideological terrorism, when it is driven by hope, cannot be fought or counteracted by appealing to interest.

35. Interest motivates more than reasonableness.

There is no reason, including mathematical certainty, which cannot be neglected, perverted, or underestimated for personal interest.

36. The hubris of reason consists in its faith in the cogency of its own epiphany. In other words, reasonableness (the epiphany of reason) is not necessary and can be insufficient (is not cogent enough) to motivate politically. Reasonableness is reconcilable with hope and interest but motivates less than either. This follows from the previous points. It is why the most rooted greed, which is based on selfish interest, cannot be fought by appealing to reasonableness. In particular, social problems-above all, corruption, fundamentalism and intolerance, exploitation and violence-and environmental problems-above all global warming, biodiversity loss, pollution, and violence on animals-cannot be solved by leveraging only reasonableness as motivation.

37. Good politics is successful if it motivates above all on the basis of hope, then of interest, and finally of reasonableness.

A winning political campaign, from Berlusconi to Trump, from Brexit to the populist movements in Italy, devalues the present, that everyone has an interest in changing as always unsatisfactory, and overestimates the future, that everyone is hoping to be better. A losing campaign, from Hilary Clinton in the US, to the Remainers in the UK, or the defeat of Renzi and his Partito Democratico (PD) in Italy, values the present as already satisfactory, often indicating how much better it is when compared to the past, ${ }^{15}$ disappointing the hopes of all those who want it to be better; and evaluates a possible future as worse or risky if the alternative wins, thus frustrating the electorate's hopes, promising only a reasonable yet unattractive more of the same (another Clinton presidency, the usual European Union, another Renzi government), that is, a losing political message.

\footnotetext{
through reflection and education about correct conduct and the obtainable virtues. Today, it refers to attempts to influence a person's behaviour, e.g. by suggesting desirable life goals.

15 See the list of U.S. presidential campaign slogans: https://en.wikipedia.org/wiki/List_of_U.S._presiden tial_campaign_slogans
} 
38. Fear is only an indirect motivational basis.

This is because anyone who has no hope, or has no interest, or does not listen to any reason, cannot be motivated by fear. Fear works only if it frustrates or threatens hope, interest, or reasonableness.

39. Punishment, understood as an instrument for the management of fear and therefore of interest, is always ineffective if it generates desperation, understood as a total lack of hope.

40. Public opinion is born of the hopes, the interests and the reasonableness of the public that expresses it.

Public opinion is rarely reasonable (it is not an expression of nous), it is often above all emotional, in terms of hopes and fears, and instinctive, in terms of interests (as an expression of doxa). Therefore, its formation is very rarely deliberative but above all psychological and hence rhetorical.

41. The rhetoric of reason is the best way to shape public opinion politically.

Good ideas alone are never enough; they need to be explained and supported in a persuasive way.

42. Good ideas are timely (they work at the right time, that is, they are kairological, the work at the right kairos) not timeless (as if they worked any time), and therefore dynamic and always updatable.

This is because the solutions they propose are not immutable, like the laws of nature, but contingent, like human history, and must evolve with the problems they face. The timeliness of good ideas is neither relative-as if it depended entirely on circumstances and always and only changed with them-nor absolute-as if it did not depend on circumstances at all, and never changed in relation to them. It is relational, because it depends in part on the circumstances and changes interactively with them, trying to improve them.

43. It is on good ideas, their priority and feasibility, that consensus must be created.

44. Consensus is the cooperative and contextual convergence of relations.

45. The two fundamental values that qualify political relations are solidarity and trust.

46. Politics as a practice is the totality of solidarity and fiduciary (trust-based) relations that organize and guide a society.

47. Solidarity regulates needs in a society and is at the root of green (environmental and ecological) solutions.

This is solidarity understood as the mutual care of relations with others, with the world, and with future generations. Without this solidarity there is only a free market but no fair prosperity.

48. Trust regulates actions in a society and is at the root of blue (digital) solutions. This is about trusting ourselves, each other, the future, human ingenuity and its products, and the potential goodness of their applications. Without this trust there is only management of political power and a market of people's views, but not also a good policy and a market of ideas.

49. Politics takes care of the relations that make up and connect things.

Focusing on the primacy of relations rather than on the primacy of things-for example, on the primacy of the concept of "citizenship" rather than that of 
"citizen"-means that good politics must move from taking care of the good management of the res publica to taking care first of all of the nature and the healthy growth of the relational network that constitutes a society, its members, and its environment, that is, the ratio publica, as previously defined. The fabric of the ratio publica is the inter-spatiality of historical-cultural relations that give identity to a society and its members.

50. Criminal politics is a form of mafia.

Mafia replaces politics in taking care of the relations that make up and connect things. This is why it is incompatible with the State and survives only by becoming an alternative form of governance.

51. Politics, when it does not work, can only be repaired if its relational nature is repaired.

Politics is malfunctioning when the two main relations of solidarity and trust do not work. It can only be repaired by repairing the two relations. This should be a reason for some comfort and moderate optimism, because it is easier to repair relations than the relata, that is, the things constituted and connected by the relations. For example, it is easier to repair the relation of trust between two political parties than "repair" the political parties themselves to make a relation of trust work.

52. Good politics is metaprojectual, that is, it supports the individual human project.

Every individual is a path of self-realization, through which a person progressively becomes more and more himself or herself. This individual, open and autonomous construction (poiesis) of the self is a delicate process because every individual does not exist in their own right and alone, but comprises a knot of relationships, fragile, flexible, and easily influenced and damaged. Politics supports individual self-construction (autopoiesis), providing the conditions for its realization, especially in terms of tolerance, justice, peace, freedom, security, education, respect and recognition of others, and equal opportunities. Politics is malfunctioning when any of these conditions is not met.

53. Good politics support the human social project.

Every society is in constant tension, even if only implicitly, towards the realization of what it would and should be, that is, as a shared and shared human project, which is an open-ended work in progress. Politics is concerned with supporting and implementing the best possible human social project, in a critical and conscious way, that is compatible with the historical circumstances in which it arises, and the individual human projects of which it takes care.

54. A fundamental value promoted by good politics is just tolerance.

Starting from Locke, tolerance lies at the root of the modern political era, as a request to keep every individual and social human life always open to choice, change, and rethinking. Tolerance must be just, i.e. attentive to the negative effects of its excessive application. But justice itself must be tolerant of difference, of error, of the possibility of doing otherwise or better, of starting again, and should not rely on the excessive application of protocols and automatisms. Justice recognizes the logical superiority of tolerance when it assumes, as its 
own limit, the acceptance of unjust injustice rather than unjust punishment: better a criminal outside prison than an innocent in prison. Hegel was right (pereat mundus ne fiat iustitia) not Kant (fiat iustitia, pereat mundus).

55. The exercise of just tolerance promotes the care for human fragility.

56. Respect for human fragility should be a universal right.

Individuals are delicate informational organisms, open and adaptable to change, malleable by education and imitation, transformed by events, changed by circumstances, influenced by the flow of information and the informational environments in which they find themselves. The first duty of politics is to ensure that human fragility is always respected and never exploited or abused.

57. Politics does not log out.

Socio-political relations can be modified but not denied. So, the rhetoric of being inside or outside (for example of Europe) is made hollow by the fact that, in a global relational network (cosmopolitanism), one cannot be disconnected, but only connected, and this in a more or less correct and coherent way with the social human project pursued. Bad politics does not disconnect (log out) but badly connects (short-circuits) the social relations and interfaces that must facilitate and coordinate them. The impossibility of politics to log out is the new embodiment of the old-fashioned, Aristotelian idea of politics being always-on. The continuous political nature of everything that happens in a society (no logout) should not be confused with the discontinuous political nature of social engagement (politics is now on-demand).

58. Politics is cybernetics.

In Plato, the kybernetes or "steersman" is the pilot of the ship, which navigates in the right direction, even against the current or unfavourable winds, and therefore sometimes indirectly and obliquely. Politics' main task is not to manage the speed of change (for example technological innovation), but to determine the goodness of the direction of change. It may or may not have a foot on the brake or the accelerator, but it must have hands on the steering wheel. The high speed with which a society proceeds in its transformations can be a good thing, if the direction chosen by politics is the right one.

59. Politics is Markovian.

Like a chess game, politics is constrained by the past, but it knows only the present, to be managed and negotiated (and in case criticised), and the future, to be designed and planned (and in case promised). This is so because voters have no memory. Whatever politics delivered in the past, whether a problem or a solution, is taken for granted. The only past that is present in the voters' minds is unrelated to history and is part of a story-telling. So those who shape the narrative of the political past control its impact.

60. Democratic politics is binary.

Democracy is usually defined in terms of the shared values (semantics) or rules (syntax) adopted by a society. In reality, semantics and syntax presuppose a previous structural step of separation between two elements: sovereignty (possession of political power) and governance (the exercise of political power). Without this binary structural condition, a democracy flattens out into a dicta- 
torship, in which the majority (which owns and exercises political power) imposes its will on the minority, whose individual or collective human project is not protected.

61. The space of politics is part of the infosphere.

Today the space of politics-understood also as public space (see above) and as a deliberative exercise-is always onlife: partly online and partly offline, partly analogue and partly digital. And it is so also for those who are still excluded from the digital revolution (those on the wrong side of the digital divide), because their choices are conditioned, influenced, or determined by those who are included.

62. Good politics today must make capitalism sustainable and fair.

Capitalism is the best system known to date to produce wealth, but not to produce it in a sustainable way (in terms of environmental impact) and to distribute it fairly (in terms of social equality). Good politics rectifies robustly these two limits, while supporting private property, project ownership, competition, innovation, investment, and profit.

63. Good politics today must replace consuming the world with fostering it.

In the past, capitalism has been seen as an inseparable counterpart to linear consumerism: producing, using, consuming, and disposing of things. But now this link can and must be severed, in favour of a new coordination between capitalism and the economy of caring for the world (that is, circular fostering). Moving from a politics of things to a politics of relations, it is easier to start building a post-materialist and post-consumeristic society, which privileges a circular economy of services and experiences in a fair and sustainable way.

64. Good politics organizes and manages a capital of citizenship.

Every generation enjoys the work, the efforts, and the sacrifices made by all the countless past generations, because each generation is the heir of past humanity and in turn leaves its legacy to the next generation. Politics in the twentyfirst century should adopt strategies to distribute and capitalise on the benefits of inherited wealth, guaranteeing to members of society not only equal opportunities but also a capital of citizenship to support individual projects.

65. The State is an interface that performs a function of relational support for the creative and fruitful strategies implemented by a society.

The State is not the point of arrival of the legal-political organization of a polity-which we have seen to be a political community, that is, the political ordering of a society-but the relational meeting point-that is, a dynamic interface, that can be realised in a variety of ways-between polities, that is, between a society that organizes itself through it, and the other societies, organized like other States, in the rest of the world. Citizens interact politically among themselves and with the world through the interface-State, to which they belong, and the various interfaces within the State (e.g. at the regional or city level). Different dynamic interfaces allow this interaction and communication, which does not require a single model at all-think of the various models of State organization, for example federations, presidential republics, constitutional monarchies, and so on. In the digital age and globalization, it may seem that 
the State no longer has a key function, and that the alternative is either a more rooted localization and corresponding micro-nationalisms-see the many phenomena of independence in various European States, from Spain to Great Britain, from Germany to Italy-or a multinational globalization consonant with markets, large companies, and intergovernmental institutions. In reality, the greater the globalization, the more necessary is the State, understood as an interface of communication, interaction, and coordination between local and global realities. The crisis of the modern State is not a crisis of "necessity" but of "sufficiency": the State is increasingly necessary, but also increasingly insufficient, to take care of the ratio publica. It is joined by many other equally necessary agents: supranational organizations, international institutions, and multinational companies.

66. A State is good when it implements good politics.

67. Good politics is multiagent.

The State has the convening power and the duty to coordinate (infraethics) other agents to take care of the ratio publica. Above all, the State should call all the stakeholders, including the corporate world, to share the responsibility, in a visible (transparency) and responsible (auditable accountability) way, of making policies together, in a multiagent pact guaranteed and managed by the State itself. This is also true at the supranational level, where the European Union, for example, has the strength and the duty to coordinate other States and stakeholders to take care of the European ratio publica.

68. Good economic policy is an economy of onlife experience.

The time available and its quality are the most important (finite, non-transferable, and non-renewable) resource for every individual. Therefore, the prosperity of individuals, their societies, and their environments is also assessed on the basis of the management and enrichment of their individual and social time. The modern era is widely interpreted as the period during which humanity has managed to "heal" more and more time-especially thanks to the improvement of living standards, scientific research, and national health systems-and to "free" more and more time-especially thanks to the various phases of industrialization and technological development, to trade, and to socio-political conditions. We live longer and better than any other past generation; and we live with much more time and income at our disposal. This is why, today, an innovative economy of growth should focus on the management and enrichment not so much of working time, but of healthy or healed time-that is, the time spent without suffering and illness-and of leisure or liberated time-that is, the disposable time (in analogy to disposable income), which is available and onlife, not bound by work commitments, and usable, that is allocable to activities of choice. In a world in which healthy time and free time will increasingly expand, the corresponding economic activities linked to their intelligent management and their fruitful use will be increasingly crucial. The future of advanced economies is not in the consumption of things but in the enjoyment of experiences. 
69. The solutions of good politics are green and blue.

The marriage between nature (phusis) and technology (techne) is vital for the prosperity of the planet, its inhabitants, and therefore every society. Today, the solutions found by good politics, in order to design and pursue the human project for a mature information society, must be both green (environmental and cultural economy and policy), and blue (digital economy and information policy). Environmental, artificial, cultural and digital environments must be fostered to ensure that they coexist in symbiotic relationships of mutual benefit. Not only must they be protected, but they must also be valued as resources for individual and social well-being, and not wasted. And they must be taken care of in a holistic way. This also means that the mentality of the exclusive protection and care of environmental and cultural assets-the environment and culture as a burden and cost for society, education included-should be transformed into an economic strategy of promotion and utilisation, seeing the environment and culture as precious capital to be put to use, for the benefit of the whole society that expresses it, and dependent on digital technologies.

\section{Conclusion}

When we talk about the digital revolution it is natural to ask ourselves what the next radical transformation will be. Human history certainly does not end here, and there will be other extraordinary changes that we cannot even imagine. These are real unknown unknowns. Just think of what we would have answered, say, in 1920, if someone had asked us to predict the future in 2020. It is simply unimaginable what the world will be like in 2120 . That said, the right perspective is that digital technologies will certainly bring other incredible innovations, but the transformation from an entirely analogical world to one that is also (and in some places, perhaps above all) digital has already happened. More will happen, but not this. Our questioning is a bit like wondering what else to expect after arriving on a new continent. We have "landed" on the digital, and we have mapped only the coasts (to continue the analogy), but the historical step has been taken. A small one for this generation, but a giant leap for future ones. So now the most important revolutionary challenge is understanding what to do with this new continent, all to be built. In other words, the new real challenge is not digital innovation but the governance of the digital. Digital governance is currently delegated (or abrogated) to the corporate world-primarily American-which follows a logic of profit-seeking and implements an entrepreneurial culture. This is fine in itself, but it is also an unsatisfactory solution as a whole because it risks ending up as a colonising monopoly-while missing the immense, counterbalancing contribution from (and to) the rest of society. However, to support and complement a necessary but insufficient corporate governance of the digital, we need above all good political strategies and courage in making the right social choices. In other words, there is a great need for good politics. 


\section{Bibliography}

Blondell, R. (2005), “From Fleece to Fabric: Weaving Culture in Plato’s Statesman”, in: Oxford Studies in Ancient Philosophy 28, 23-75.

Cassirer, E. (1923), Substance and function, and Einstein's theory of relativity, Chicago.

Floridi, L. (2015), "Toleration and the Design of Norms", in: Science and Engineering Ethics 21 (5), 10951123.

- (2016), “Tolerant Paternalism: Pro-ethical Design as a Resolution of the Dilemma of Toleration”, in: Science and Engineering Ethics 22 (6), 1669-1688. doi: 10.1007/s11948-015-9733-2.

- (2019), The Logic of Information: A Theory of Philosophy as Conceptual Design, Oxford.

- (2020), Il Verde e il Blu - Idee ingenue per migliorare la politica, Milan.

Halmos, P. R. (2017), Naive set theory, Mineola/New York.

Oxford Internet Institute

University of Oxford

1 St Giles

Oxford, OX1 3JS

United Kingdom

The Alan Turing Institute

96 Euston Road

London, NW1 2DB

United Kingdom

luciano.floridi@oii.ox.ac.uk 